\title{
Ligand-assisted preparation of highly active and stable nanometric Pd confined catalysts for deep catalytic oxidation of toluene
}

\author{
Chi He, Peng Li, Hailin Wang, Jie Cheng, Xinyan Zhang, Yufei Wang, Zhengping Hao* \\ Department of Environmental Nano-Materials, Research Center for Eco-Environmental Sciences, Chinese Academy of Sciences, No. 18 Shuangqing Road, \\ PO Box 2871, Beijing 100085, China
}

\section{A R T I C L E I N F O}

\section{Article history:}

Received 22 March 2010

Received in revised form 22 May 2010

Accepted 24 May 2010

Available online 1 June 2010

\section{Keywords:}

Ligand-assisted

Highly dispersed Pd

SBA-15

VOCs

Catalytic oxidation

\begin{abstract}
A B S T R A C T
In this study, mesoporous SBA-15 supported Pd catalysts were synthesized through impregnation and grafting approaches. Moreover, the influences of different solvents (ethanol, $\mathrm{H}_{2} \mathrm{O}$, tetrahydrofuran, dimethyl sulphoxide and $\mathrm{N}, \mathrm{N}$-dimethylformamide) on the dispersion of supported Pd nanoparticles were also systematically investigated. The prepared materials were comprehensively explored by various techniques, including XRD, EDS, ICP-OES, $\mathrm{H}_{2}$ chemisorption, $\mathrm{N}_{2}$ adsorption/desorption, TG-DSC, FT-IR, TEM and STEM. It is found that the traditional impregnation method has some disadvantages in obtaining highly dispersed Pd active phase. Whereas, the grafting method could highly disperse Pd nanoparticles within the mesoporous channels of support material, and the grafting procedure should be promising in designing highly dispersed Pd particles on the silica-based mesoporous materials. The catalyst prepared via the grafting procedure possesses much higher activity and selectivity than that prepared by impregnation method for deep catalytic oxidation of toluene.
\end{abstract}

(c) 2010 Elsevier B.V. All rights reserved.

\section{Introduction}

Industrial waste gases emitted from chemical and petrochemical plants contain different types of hazardous volatile organic compounds (VOCs). Among them, benzene, toluene and xylene are of particular concern due to their high toxicity for human beings [1-3]. The deep catalytic oxidation of these pollutants to $\mathrm{CO}_{2}$ and $\mathrm{H}_{2} \mathrm{O}$ has been identified as one of the most efficient ways to eliminate VOCs $[4,5]$.

On the other hand, the proper selection and development of the catalyst is essential for successful removal of VOCs. Currently, VOCs catalytic oxidation has been widely investigated over different types of catalysts, such as supported noble metals, metal oxides, and mixtures of noble metals and metal oxides [6,7]. Particularly, Pd-loaded catalysts are extensively examined considering their superior activity and high tolerance to moisture [8]. As is known, support material is an important component for the noble metal-loaded catalysts [9]. Up to now, different types of supports, such as porous materials, zirconia, alumina and silica are comprehensively investigated in hydrocarbons catalytic oxidation [10-12]. Among them, mesoporous materials (such as SBA-15 and MCM-48) possess narrow pore size distribution, high surface area, and potential ability to inhibit active particles growth and aggregation in their

\footnotetext{
* Corresponding author. Tel.: +86 10 62849194; fax: +861062923564.

E-mail addresses: zpinghao@mail.rcees.ac.cn, zpinghao@rcees.ac.cn (Z. Hao).
}

pores [13], appear to be one of the best supports for Pd-loaded catalysts.

Recent work suggested that highly dispersed Pd nanoparticles are extraordinarily active and may exhibit unique properties in a wide range of important chemical processes [2,14,15]. Various strategies were developed for incorporating metal nanoparticles into mesoporous silica, which could be generally classified into three groups: (1) chemical vapor deposition of metal precursors into the silica frameworks [16,17]; (2) wet impregnation or ion exchange of the appropriate metal salt into the host silica, followed by thermal treatment and reduction procedure [18,19]; and (3) synthesis of the mesoporous materials around the pre-prepared metal nanocrystals [20]. However, it is very difficult to control the status, such as location, size and shape of metal nanoparticles by aforementioned approaches. For example, the Pd/SBA-15 materials were synthesized by Byeon and co-workers using a simple impregnation method [21]. However, this method could not ensure the encapsulation of Pd nanoparticles inside the mesoporous channels, and hence large metal aggregates would form on the external surface of SBA-15 during thermal treatment or reaction. Besides, chemical vapor deposition was once used for the preparation of Pd/SBA-15 materials, but Pd nanowires were mainly obtained [22]. Therefore, the exploration of new preparation methods is still very urgent. Liu and co-workers [13] synthesized the monodispersed Pd nanoparticles in the interior surface of SBA-15 channels via a glow discharge plasma reduction approach, but the average Pd particle size was still unsatisfactory (ca. $8.2 \mathrm{~nm}$ ). Zhang and co-workers [23] 
prepared highly dispersed Pd/SBA-15 catalysts (Pd size $=3-4 \mathrm{~nm}$ ) using a simple adsorption method under alkaline conditions. However, the host SBA-15 was unstable in alkaline solution and the location of Pd nanoparticles could not be controlled accurately. Recently, Jiang and co-workers [24] developed an effective method to synthesize highly dispersed Ag encapsulated materials by selectively functionalizing the outer and the inner surfaces of SBA-15. Besides, Dai and co-workers [25] reported that solvents had significant influences on the dispersion of supported Au nanoparticles over silica-based mesoporous materials. Unfortunately, the synthesis of highly dispersed Pd nanoparticles confined in SBA-15 interior surface and the solvent effects on Pd dispersion was seldom explored.

In this work, we try to develop highly active and stable nanometric Pd confined catalysts for toluene elimination. The primary objectives of this paper are as follows: (1) to investigate the flexibility of the grafting approach for the synthesis of highly dispersed Pd nanoparticles confined in mesoporous SBA15 channels; (2) to examine whether the solvents (ethanol, $\mathrm{H}_{2} \mathrm{O}$, tetrahydrofuran (THF), dimethyl sulphoxide (DMSO) and $\mathrm{N}, \mathrm{N}-$ dimethylformamide (DMF)) affect the dispersion of Pd atoms; (3) to explore the application prospect (activity, selectivity and stability) of the synthesized catalysts in the elimination of toluene. To the best of our knowledge, such a systematic study has not been reported.

\section{Experimental}

\subsection{Catalyst preparation}

The Pd confined catalysts were synthesized according to the following four sub-steps, as illustrated in Fig. 1. Firstly, hydroxyls on the external surface of as-synthesized SBA-15 (containing P123 template) were capped by the $-\mathrm{Si}\left(\mathrm{CH}_{3}\right)_{3}$ groups; Secondly, the P123 template in the pore channels of assynthesized SBA-15 was removed by ethanol extraction; Thirdly, the $-\mathrm{Si}\left(\mathrm{CH}_{2}\right)_{3} \mathrm{NH}_{2}$ groups were introduced into the internal surface of mesoporous SBA-15 through the grafting reaction between 3aminopropyltrimethoxysilane (APTMS) and SBA-15; Fourthly, the Pd nanoparticles were grafted into the pore channels of SBA- 15 by molecular interaction between Pd and amino groups.

Mesoporous SBA-15 was synthesized following the literature procedure [26]. Typically, $4 \mathrm{~g}$ of $\mathrm{P} 123,135 \mathrm{~g}$ of $\mathrm{H}_{2} \mathrm{O}, 24 \mathrm{~g}$ of $\mathrm{HCl}$ and $9.1 \mathrm{ml}$ of TEOS were mixed under stirring at $35^{\circ} \mathrm{C}$ for $20 \mathrm{~h}$, and then aged at $100^{\circ} \mathrm{C}$ for $48 \mathrm{~h}$. The recovered solid was washed and dried to obtain the as-SBA-15 sample. The template was removed by calcination in air at $350^{\circ} \mathrm{C}$ for $3 \mathrm{~h}$ and then at $550^{\circ} \mathrm{C}$ for $4 \mathrm{~h}$ to obtain the final product.

$1.0 \mathrm{~g}$ of as-SBA-15 was suspended in $75 \mathrm{ml}$ of dry toluene under flowing $\mathrm{N}_{2}$, and then $5.0 \mathrm{ml}$ of TMCS was added dropwise under stirring. After the mixture was stirred at $80^{\circ} \mathrm{C}$ for $8 \mathrm{~h}$, the solid was recovered after washing with toluene and then with ethanol intensively to eliminate the physically adsorbed TMCS and toluene. The P123 template was removed with ethanol in a Soxhlet extractor at $100^{\circ} \mathrm{C}$ for $24 \mathrm{~h}$ and dried in vacuum at $80^{\circ} \mathrm{C}$ for $8 \mathrm{~h}$. Finally, the mesoporous silica with the external surface capped with $-\mathrm{Si}\left(\mathrm{CH}_{3}\right)_{3}$ (denoted as T-SBA-15) was collected. $1.0 \mathrm{~g}$ of T-SBA-15 was dispersed in $75 \mathrm{ml}$ of dry toluene after having been dried at $80^{\circ} \mathrm{C}$ for $12 \mathrm{~h}$, and then $3.0 \mathrm{ml}$ of APTMS was added under stirring. The obtained mixture was stirred for another $12 \mathrm{~h}$ at room temperature and refluxed at $80^{\circ} \mathrm{C}$ for $8 \mathrm{~h}$. The solid was obtained after washing with toluene and then with ethanol intensively to eliminate the physically adsorbed APTMS and toluene. The modified sample after being vacuum-dried at $80^{\circ} \mathrm{C}$ for $6 \mathrm{~h}$ was labeled as A-T-SBA-15. To introduce Pd, $1.0 \mathrm{~g}$ of A-T-SBA-15 was added into a mixture of $x$ (solvents: $x=$ ethanol, $\mathrm{H}_{2} \mathrm{O}, \mathrm{THF}, \mathrm{DMSO}$ or DMF) and $3.9 \mathrm{ml}$ of $\mathrm{PdCl}_{2}$

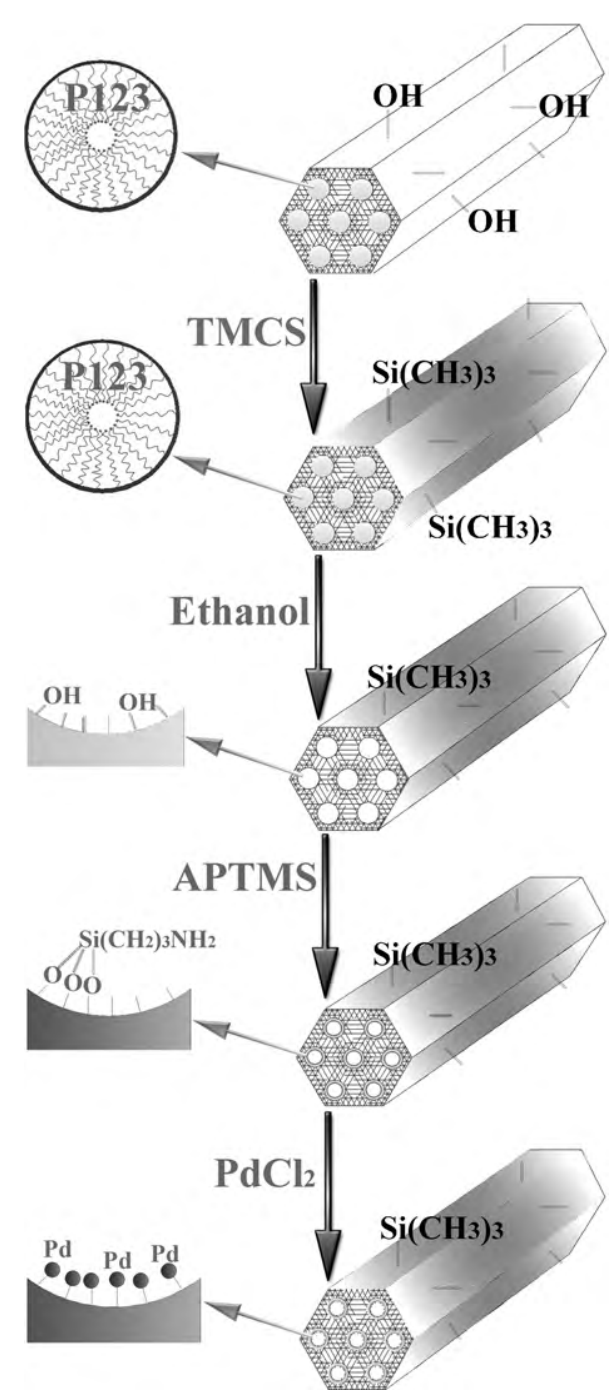

Fig. 1. Schematic representation for synthesis of Pd confined catalysts.

solution $\left(2.55 \mathrm{mg} \mathrm{Pd} / \mathrm{ml}, x / \mathrm{PdCl}_{2}=4: 1, \mathrm{v} / \mathrm{v}\right)$. And the mixture was then stirred at room temperature for $2 \mathrm{~h}$, dried at $40^{\circ} \mathrm{C}$ for $24 \mathrm{~h}$, followed by calcination at $550^{\circ} \mathrm{C}$ for $2 \mathrm{~h}$ and reduction in a pure $\mathrm{H}_{2}$ stream $(30 \mathrm{ml} / \mathrm{min})$ at $480^{\circ} \mathrm{C}$ for $1 \mathrm{~h}$ to obtain the nanometric Pd confined catalyst. The collected catalysts were denoted as GtPdS-E (solvent: ethanol), GtPdS-H (solvent: $\mathrm{H}_{2} \mathrm{O}$ ), GtPdS-T (solvent: THF), GtPdS-DO (solvent: DMSO) and GtPdS-D (solvent: DMF), respectively.

For comparison, the Pd-supported catalyst was also prepared by impregnation method. The mesoporous SBA-15 was impregnated with a $\mathrm{PdCl}_{2}$ aqueous solution and dried at $40^{\circ} \mathrm{C}$ for $24 \mathrm{~h}$, followed by calcination at $550^{\circ} \mathrm{C}$ for $2 \mathrm{~h}$ and reduction in a pure $\mathrm{H}_{2}$ stream $(30 \mathrm{ml} / \mathrm{min})$ at $480^{\circ} \mathrm{C}$ for $1 \mathrm{~h}$ to obtain the catalyst ImPdS. The nominal Pd loading of all catalysts were $1.0 \mathrm{wt} . \%$.

\subsection{Material characterizations}

X-ray diffraction (XRD) patterns were recorded on a PANalytical X'Pert PRO powder diffraction system using $\mathrm{Cu} \mathrm{K} \alpha$ radiation $(\lambda=0.15418 \mathrm{~nm})$ in the $2 \theta$ range of $0.7-5^{\circ}$ (scanning rate of $0.5^{\circ} / \mathrm{min}$ ) and $10-80^{\circ}$ (scanning rate of $4 \% \mathrm{~min}$ ), respectively. Energy dispersive spectrometer (EDS) was performed on a Hitachi $\mathrm{S}-3000 \mathrm{~N}$ for composition analysis of the synthesized catalysts. The exact Pd loading was determined by inductively coupled plasma optical emission spectroscopy (ICP-OES) on a PerkinElmer OPTIMA 
2000. The palladium dispersion was assessed on Micromeritics CHEMISORB 2720 by $\mathrm{H}_{2}$ chemisorption at $25^{\circ} \mathrm{C}$, i.e., the molar ratio of $\mathrm{H} / \mathrm{Pd}$ [27]. The mean Pd crystallite size was further estimated from the equation: $d(\mathrm{~nm})=112 /$ (percentage of Pd exposed) [28], assuming that the Pd crystallites were spherical with a surface atom density of $1.27 \times 10^{9}$ atoms/m² $\mathrm{N}_{2}$ adsorption/desorption isotherms of catalysts at $77 \mathrm{~K}$ were collected on a Quantachrome NOVA 1200 gas sorption analyzer. The total pore volume was estimated from the amount of nitrogen adsorbed at a relative pressure $\left(P / P_{0}\right)$ of $c a$. 0.99 . The specific surface area $\left(S_{\mathrm{BET}}\right)$ was calculated using the Brunauer-Emmett-Teller (BET) method and the pore size distribution (PSD) was derived from the desorption branch of the
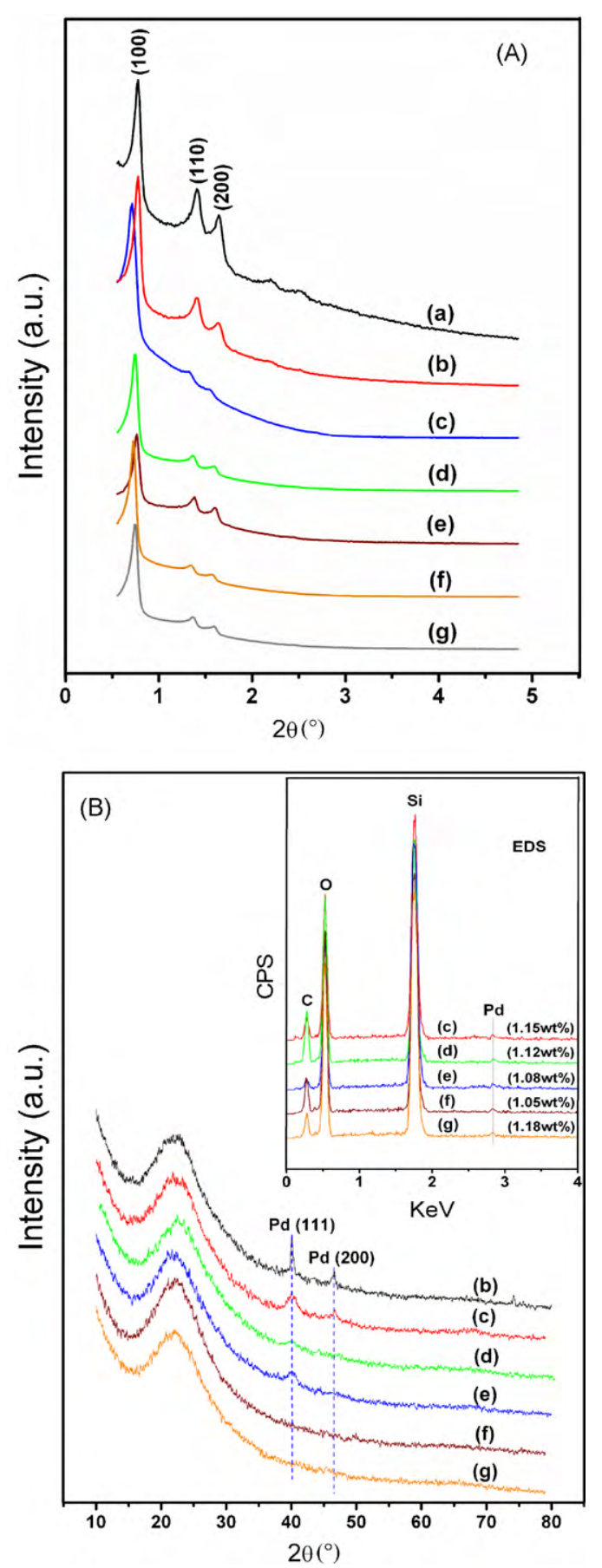

Fig. 2. SA-XRD, WA-XRD and EDS (insert) patterns of (a) SBA-15, (b) ImPdS, (c) GtPdS-E, (d) GtPdS-H, (e) GtPdS-T, (f) GtPdS-DO and (g) GtPdS-D.
$\mathrm{N}_{2}$ isotherm using the Barrett-Joyner-Halenda (BJH) method. Thermogravimetric analysis (TGA) was performed on a Setaram Labsys, where ca. $10 \mathrm{mg}$ of finely ground sample was heated from 30 to $800^{\circ} \mathrm{C}$ at a heating rate of $10^{\circ} \mathrm{C} / \mathrm{min}$ with air flowing at $30 \mathrm{ml} / \mathrm{min}$. Fourier transform infrared (FT-IR) spectra were recorded using a Bruker Tensor 27 IR spectrometer. Transmission electron microscope (TEM) images were recorded on a Hitachi H-7500 microscope operating at an accelerating voltage of $80 \mathrm{kV}$. Scanning transmission electron microscope (STEM) images were recorded on a FEI Tecnai G2 F20 U-TWIN microscope operating at an accelerating voltage of $200 \mathrm{kV}$. All samples were ground, dispersed in ethanol and deposited on the micro-grids prior to observation.

\subsection{Catalytic oxidation activities}

All evaluation experiments were performed in a continuousflow fixed-bed reactor at atmospheric pressure, consisting of a stainless steel tube ( $6 \mathrm{~mm}$ i.d.) that was filled with the catalyst. The toluene-containing gas was generated by bubbling air through the toluene saturator, and then further diluted with another air stream before reaching the reaction bed. The temperatures of the catalyst bed and tubular electric furnace were monitored automatically by E-type thermocouples (E-161, Shenyang Zhongse Thermometer Plant). In each test, $200 \mathrm{mg}$ of the catalyst (40-60 mesh) was placed at the middle of the tube reactor and the total flow rate was kept at $350 \mathrm{ml} / \mathrm{min}$, i.e., gas hourly space velocity (GHSV) of $45,000 / \mathrm{h}$, and the $\mathrm{O}_{2}$ feed concentration was kept at about 21 (v/v\%). In each test, the catalyst bed temperature was first raised to $130^{\circ} \mathrm{C}$ with the feed stream passing and stabilized for $30 \mathrm{~min}$. Then the temperature was increased to the next one at a heating rate of $5^{\circ} \mathrm{C} / \mathrm{min}$ and stabilized for $20 \mathrm{~min}$ prior to online analysis of the effluent gas composition in an Agilent gas chromatograph equipped with an FID and a TCD. Toluene concentrations in the feed and effluent streams were determined with the FID after being separated in an $\mathrm{AB}-\mathrm{GASPRO}$ capillary column, and $\mathrm{CO} / \mathrm{CO}_{2}$ in the effluent stream were separated in a TDX-01 column and their concentrations were determined with the TCD.

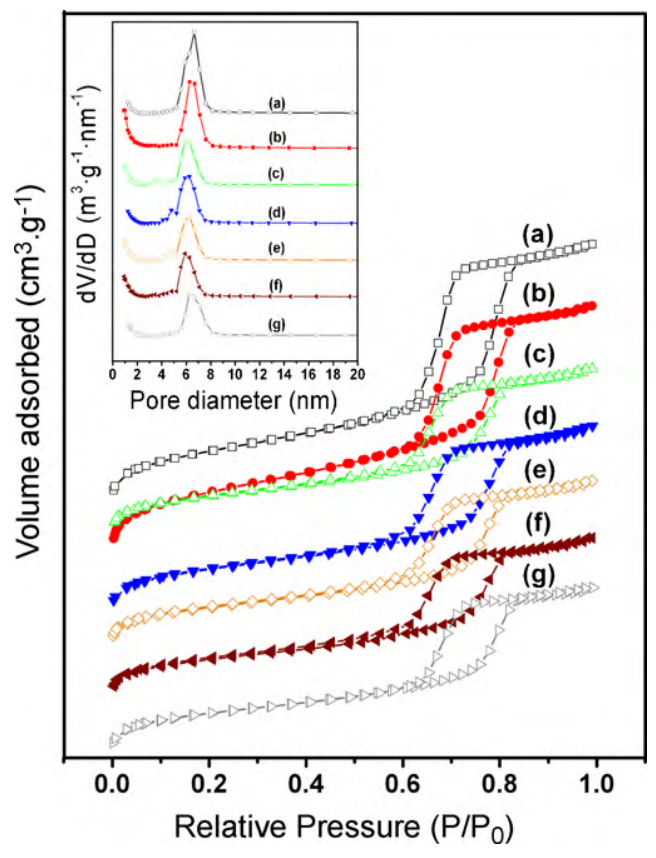

Fig. 3. $\mathrm{N}_{2}$ adsorption/desorption isotherms and pore size distribution calculated from the desorption branch (insert) of (a) SBA-15, (b) ImPdS, (c) GtPdS-E, (d) GtPdSH, (e) GtPdS-T, (f) GtPdS-DO and (g) GtPdS-D. 
Table 1

Physicochemical properties of synthesized samples.

\begin{tabular}{|c|c|c|c|c|c|c|c|}
\hline Sample & $S_{\mathrm{BET}^{\mathrm{a}}}\left(\mathrm{m}^{2} / \mathrm{g}\right)$ & $D_{\mathrm{v}}{ }^{\mathrm{b}}\left(\mathrm{cm}^{3} / \mathrm{g}\right)$ & $D_{\mathrm{p}}{ }^{\mathrm{c}}(\mathrm{nm})$ & $d_{100^{\mathrm{d}}}(\mathrm{nm})$ & $a_{0}{ }^{\mathrm{e}}(\mathrm{nm})$ & $\mathrm{H} / \mathrm{Pd}^{\mathrm{f}}$ & $D_{\mathrm{c}^{\mathrm{g}}}(\mathrm{nm})$ \\
\hline SBA-15 & 759.9 & 1.07 & 6.7 & 9.01 & 10.39 & 1 & 1 \\
\hline ImPdS & 697.2 & 0.95 & 6.4 & 9.11 & 10.51 & 0.30 & 3.73 \\
\hline GtPdS-E & 614.4 & 0.65 & 5.9 & 9.81 & 11.32 & 0.41 & 2.73 \\
\hline GtPdS-H & 613.5 & 0.66 & $4.7 / 6.1$ & 9.44 & 10.89 & 0.57 & 1.96 \\
\hline GtPdS-T & 615.8 & 0.67 & $4.6 / 6.1$ & 9.21 & 10.62 & 0.47 & 2.38 \\
\hline GtPdS-DO & 618.6 & 0.66 & 5.9 & 9.56 & 11.03 & 0.64 & 1.75 \\
\hline GtPdS-D & 623.1 & 0.68 & 6.2 & 9.51 & 10.97 & 0.66 & 1.69 \\
\hline
\end{tabular}

a BET specific surface area calculated at $P / P_{0}=0.05-0.25$.

b Total pore volume estimated at $P / P_{0}=0.99$.

c BJH pore diameter calculated from the desorption branch.

d Interplanar spacing of the (100) plane.

e Lattice parameter, $a_{0}=2 \times d_{100} / \sqrt{3}$.

f Molar ratio of adsorbed hydrogen atoms to the total palladium atoms.

$\mathrm{g}$ Calculated diameters of the palladium crystallites based on the dispersion of Pd.

Table 2

Characteristic data and catalytic activity of synthesized catalysts.

\begin{tabular}{|c|c|c|c|c|c|c|c|}
\hline Sample & $\mathrm{Pd}^{\mathrm{a}}$ (wt.\%) & $T_{10}{ }^{\mathrm{b}}\left({ }^{\circ} \mathrm{C}\right)$ & $T_{50}{ }^{\mathrm{b}}\left({ }^{\circ} \mathrm{C}\right)$ & $T_{90^{b}}{ }^{\circ}\left({ }^{\circ} \mathrm{C}\right)$ & $S_{170^{\mathrm{c}}}(\%)$ & $S_{200^{c}}(\%)$ & $S_{230^{c}}(\%)$ \\
\hline ImPdS & 0.99 & 177 & 220 & 242 & 88.4 & 90.6 & 96.1 \\
\hline GtPdS-D & 0.95 & 163 & 188 & 212 & 100 & 99.3 & 100 \\
\hline
\end{tabular}

a Actual Pd contents obtained by the ICP-OES analysis.

b Temperatures at which $10 \%, 50 \%$ and $90 \%$ conversion of toluene.

c The $\mathrm{CO}_{2}$ selectivity obtained at 170,200 and $230^{\circ} \mathrm{C}$, respectively.

\section{Results and discussion}

\subsection{Structural and textural properties of the synthesized catalysts}

Fig. 2(A) shows the small-angle XRD (SA-XRD) patterns of the synthesized materials. All samples exhibit one intense peak at $0.8-1.0^{\circ}$ along with two weak peaks at $1.3-2.0^{\circ}$, which can be assigned to the (100), (110), and (200) plane reflections of the two-dimesional hexagonal mesostructure with a space group of p6mm symmetry [29], indicating that the incorporation of Pd has negligible influence on the original structure of SBA-15. However, the intensities of these diffraction peaks have a slight decrease for

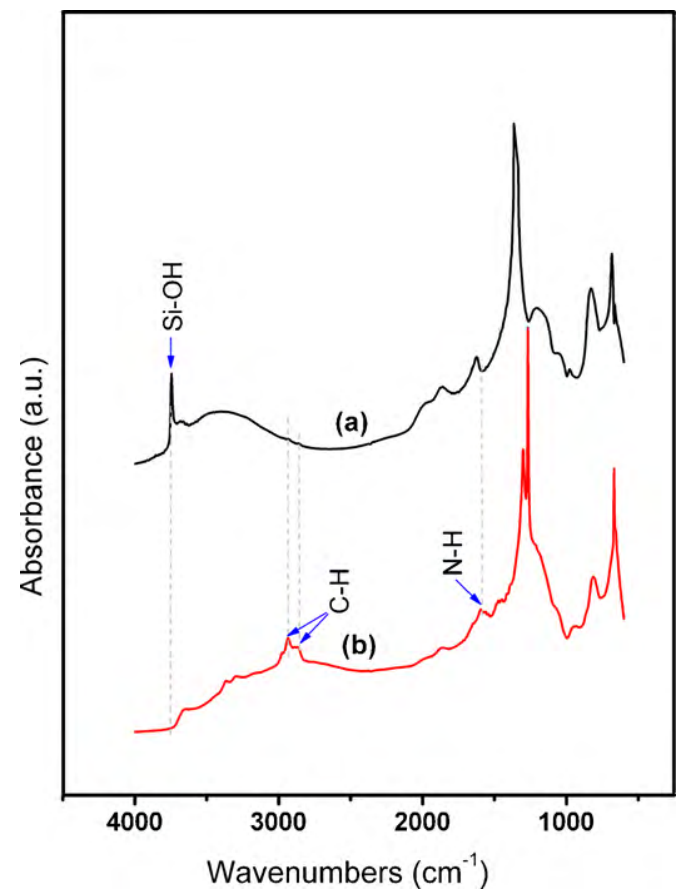

Fig. 4. FT-IR spectra of (a) SBA-15 and (b) A-T-SBA-15. samples synthesized via the grafting approach, indicating that the mesoporous channels of SBA-15 may be occupied by Pd nanoparticles [23]. By carefully comparing the patterns in Fig. 2(A), we can observe that all diffraction peaks of Pd confined samples shift slightly to lower angles, corresponding to a tiny increase of $d_{100}$ and $a_{0}$, as listed in Table 1 . This shift suggests that the frameworks of the silica host are slightly enlarged during the synthesis process [13]. The wide-angle XRD (WA-XRD) and EDS (insert) patterns of all Pdsupported catalysts are shown in Fig. 2(B). The actual Pd loading of all synthesized catalysts are close to $1.0 \mathrm{wt}$.\% (Fig. 2(B) and Table 2). The broad diffraction peak appeared at $2 \theta=23^{\circ}$ in all WA-XRD patterns can be ascribed to the amorphous silica. For ImPdS, two relatively sharp diffraction peaks can be seen at $2 \theta=40.1^{\circ}$ and $46.4^{\circ}$ in WA-XRD pattern, assigned to ( 1111$)$ and (2 000$)$ reflections of metal-

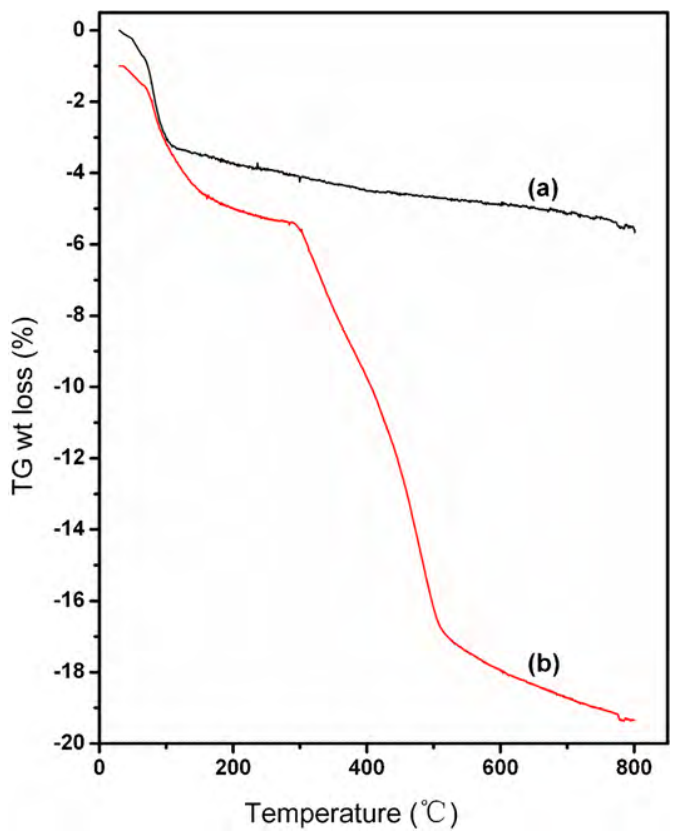

Fig. 5. Thermogravimetric analysis of (a) SBA-15 and (b) A-T-SBA-15. 
lic Pd, respectively (JCPDS: 46-1043). Overall, the diffraction peaks of Pd particles over grafting samples are weaker and broader than that of Pd-impregnated material, indicating that smaller Pd atoms are formed (according to the Scherrer equation) (Fig. 2(B)). Noticeably, the solvents have significant influences on the Pd dispersion. For instance, two broad diffraction peaks at $2 \theta=40.1^{\circ}$ and $46.4^{\circ}$ (metallic Pd) can be seen in the pattern of GtPdS-E, while these peaks become weaker and broader for GtPdS-H and GtPdS-T, and totally disappear for GtPdS-DO and GtPdS-D, as shown in Fig. 2(B).

Fig. 3 displays the $\mathrm{N}_{2}$ adsorption/desorption isotherms and the $\mathrm{BJH}$ pore size distribution calculated from the desorption branch (insert) for all synthesized materials. Both of the samples possess type IV isotherms (characteristic of mesoporous materials) and exhibit a H1 type hysteresis loop according to the IUPAC classification [30]. The structure data of SBA-15 and Pd/SBA-15 samples are summarized in Table 1 . Comparing with pure SBA15 , the $S_{\mathrm{BET}}, D_{\mathrm{v}}$ and $D_{\mathrm{p}}$ of ImPdS have a slight decrease, from $759.9 \mathrm{~m}^{2} / \mathrm{g}, 1.07 \mathrm{~cm}^{3} / \mathrm{g}$, and $6.7 \mathrm{~nm}$ to $697.2 \mathrm{~m}^{2} / \mathrm{g}, 0.95 \mathrm{~cm}^{3} / \mathrm{g}$, and $6.4 \mathrm{~nm}$, respectively. However, the $S_{\mathrm{BET}}, D_{\mathrm{v}}$ and $D_{\mathrm{p}}$ of Pd-grafted samples decrease obviously, suggesting that the Pd nanoparticles are incorporated into the pore channels of SBA-15, This is in good agreement with the XRD results (Fig. 2).

FT-IR spectra of SBA-15 and A-T-SBA-15 are displayed in Fig. 4. Pure SBA-15 shows characteristic bands at about 1630 and $3741 / \mathrm{cm}$, indicating the presence of stretching vibrations of isolated $\mathrm{O}-\mathrm{H}$ bonds and $\mathrm{Si}-\mathrm{OH}$ groups, respectively [31]. For A-T-

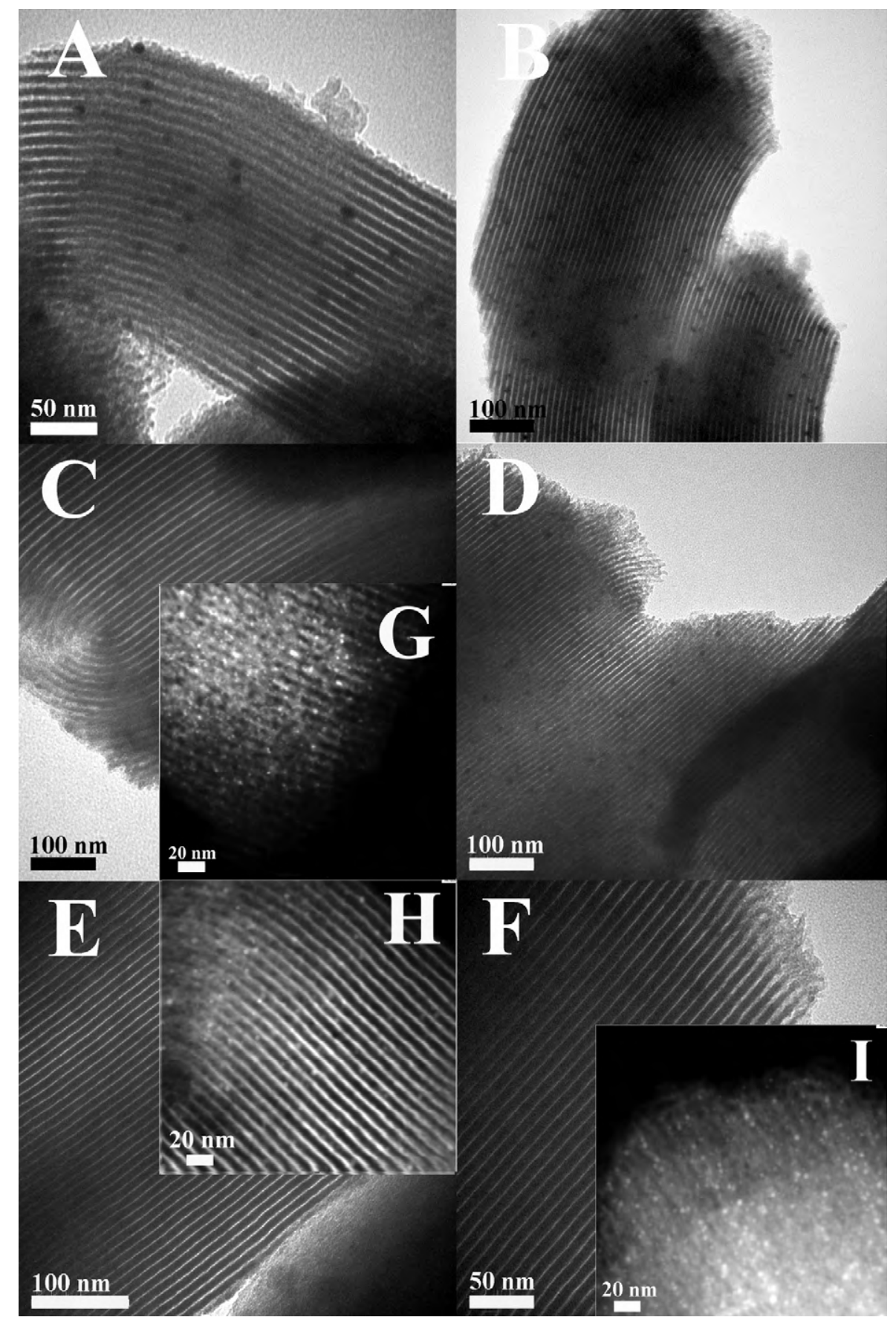

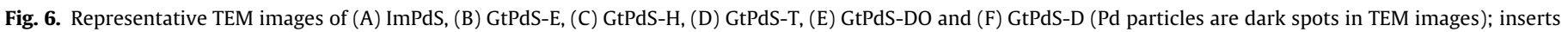
are STEM images of (G) GtPdS-H, (H) GtPdS-DO and (I) GtPdS-D (Pd particles are light spots in STEM images). 
SBA-15 sample, the peak at $3740 / \mathrm{cm}$ has disappeared, and three new infrared absorption bands at 1602, 2863 and 2900/cm have appeared. The absorption peak centered at $1602 / \mathrm{cm}$ is attributed to the $\mathrm{N}-\mathrm{H}$ asymmetric bending [32], and the peaks between 2700 and $2900 / \mathrm{cm}$ can be assigned to the $\mathrm{C}-\mathrm{H}$ stretching [33], indicating that the $-\mathrm{Si}\left(\mathrm{CH}_{2}\right)_{3} \mathrm{NH}_{2}$ was created on the inner surface of SBA-15 channels when T-SBA-15 was treated with APTMS. Fig. 5 shows the TG curves of SBA-15 and A-T-SBA-15 samples. The first weight loss below $120^{\circ} \mathrm{C}$ is due to the desorption of physicsorbed water, and the weights of both samples then slowly decreased up to about $300^{\circ} \mathrm{C}$ is attribute to the further desorption of water or the removal of small amounts of residual template [34]. Besides, an obvious weight loss in the range of $300-520^{\circ} \mathrm{C}$ can be observed in A-T-SBA-15 (ca. 13 wt.\%), while no evident weight loss occurs in SBA-15, indicating the decomposition of functional groups. The small weight reduction between 520 and $800^{\circ} \mathrm{C}$ ( $\mathrm{ca}$. $1.6 \mathrm{wt}$.\%) over A-T-SBA-15 can be assigned to the further decomposition of some residual functional groups.

The representative TEM and STEM (insert) images of all synthesized materials are shown in Fig. 6. The result reveals that all synthesized catalysts have well-ordered mesoporous channel structure, which supports the aforementioned SA-XRD and $\mathrm{N}_{2}$ sorption results (Figs. 2 and 3). Spherical Pd nanoparticles with narrow distribution over ImPdS (ca. 7-10 nm) are obviously larger than that of Pd confined samples (Fig. 6). It is worth noting that the solvent has a significant effect on the dispersion of Pd particles. The average Pd particle sizes over GtPdS-E and GtPdS-T are calculated to be 5.2 and $4.7 \mathrm{~nm}$, respectively (Fig. $6 \mathrm{~B}$ and D). However, no Pd particles can be found over GtPdS-H, GtPdS-DO and GtPdS-D samples, as the Pd atoms are too small to be observed. Thus, STEM was performed to further explore the Pd dispersion over these materials, and the result reveals that the Pd particle size over GtPdS-H (ca. $3.5 \mathrm{~nm})$ is slightly larger than that of GtPdS-DO (ca. $3.0 \mathrm{~nm})$ and GtPdS-D (ca. $2.7 \mathrm{~nm}$ ), as shown in Fig. 6G-I. For grafting samples, it is interesting to note that the Pd particles are located inside the mesoporous channels of the host material (Fig. 6B-I). Besides, the dispersion of Pd nanoparticles in all samples was further evaluated by $\mathrm{H}_{2}$ chemisorption, as listed in Table 1 . The experimental result reveals that the Pd particle size over $\operatorname{ImPdS}\left(D_{\mathrm{c}}=3.73 \mathrm{~nm}\right)$ is significantly larger than that of grafting samples $\left(D_{\mathrm{C}}=1.69-2.73 \mathrm{~nm}\right)$, and the Pd dispersion order is as follows: GtPdS-D $>$ GtPdS-DO $>$ GtPdS$\mathrm{H}>\mathrm{GtPdS}-\mathrm{T}>\mathrm{GtPdS}-\mathrm{E}>\mathrm{ImPdS}$. It could be proposed that the amino groups dispersed on the inner surface of host silica chelate the Pd ions in stoichiometry. Pd ions would tend to be anchored homogeneously at the functionalized silica surface, and Pd nanoparticles formed upon calcination and reduction would be well-dispersed in the channels of host silica. Therefore, it seems that the grafting procedure is promising in designing nano-dispersed particles on the silica-based materials. While for traditional impregnation procedure, the $\mathrm{PdCl}_{2}$ aqueous solution has some difficulties in spreading over the hydrophobic silica surface [5], resulting in the poor dispersion of active phase.

\subsection{Catalytic oxidation of toluene}

The light-off curves were used to compare the activity of the synthesized catalysts for toluene oxidation, as shown in Fig. 7. Only $\mathrm{CO}_{2}, \mathrm{H}_{2} \mathrm{O}$, trace $\mathrm{CO}$ and residual toluene can be detected in the effluent. Generally, the catalysts prepared via the grafting procedure possess higher toluene oxidation activities than that of ImPdS, and GtPdS-D has the highest activity. As can be observed in Fig. 7, toluene total conversion occurs at $250^{\circ} \mathrm{C}$ for ImPdS. While for GtPdS-D, toluene total conversion becomes appreciable at $<150^{\circ} \mathrm{C}$, approaching $50 \%$ toluene conversion at $188^{\circ} \mathrm{C}$, and achieving complete conversion at $220^{\circ} \mathrm{C}$. Considering the relatively high space velocity $(45,000 / \mathrm{h})$ during oxidation reactions, it seems to be a

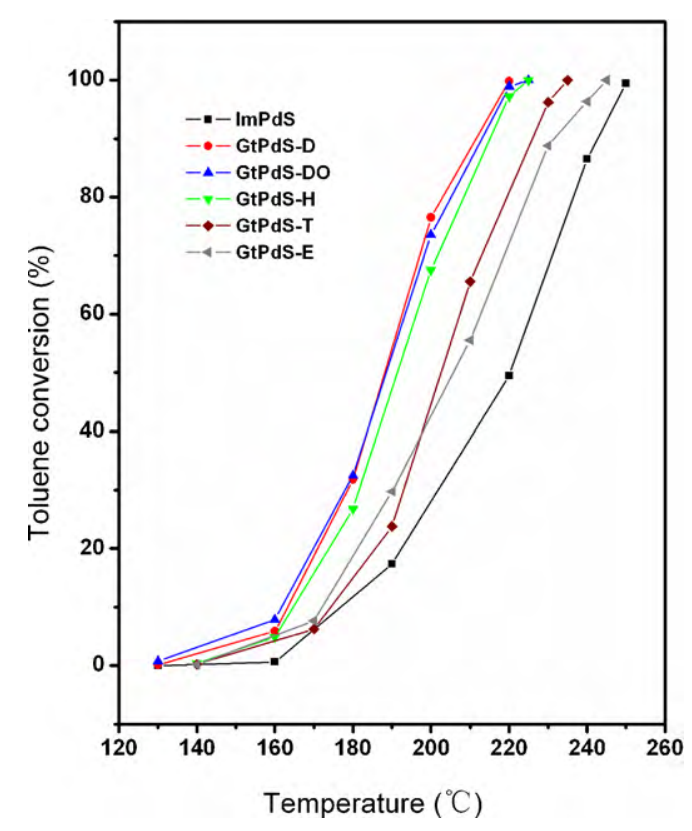

Fig. 7. Toluene conversion over various Pd-loaded catalysts.

good result for toluene elimination. In this work, the $\mathrm{CO}_{2}$ selectivity and yield during toluene oxidation over GtPdS-D and ImPdS (two representative catalysts) were further investigated. Fig. 8 shows the conversion curve and $\mathrm{CO}_{2}$ selectivity (solid line), and $\mathrm{CO}_{2}$ yield (dashed line, calculated by (mole number of $\mathrm{CO}_{2}$ produced $) / 7 \times($ mole number of toluene fed $)$ ) during toluene oxidation over GtPdS-D and ImPdS catalysts. The gap between the toluene conversion and $\mathrm{CO}_{2}$ yield for GtPdS-D is smaller than that of ImPdS, and the $\mathrm{CO}_{2}$ yield of ImPdS and GtPdS-D can reach $100 \%$ at about 260 and $230^{\circ} \mathrm{C}$, respectively (Fig. 8). Table 2 presents the toluene oxidation temperature and $\mathrm{CO}_{2}$ selectivity over ImPdS and GtPdSD. Remarkably, the $\mathrm{CO}_{2}$ selectivity of GtPdS-D (98.1-100\%) is higher than that of ImPdS (87.8-100\%) at different temperature points. As is known, achieving precise control of the Pd particle size and overall particle size distribution of catalysts is one of the most important challenges to provide excellent catalysis properties [35]. Moreover, a high activity of a supported catalyst often calls for a large active

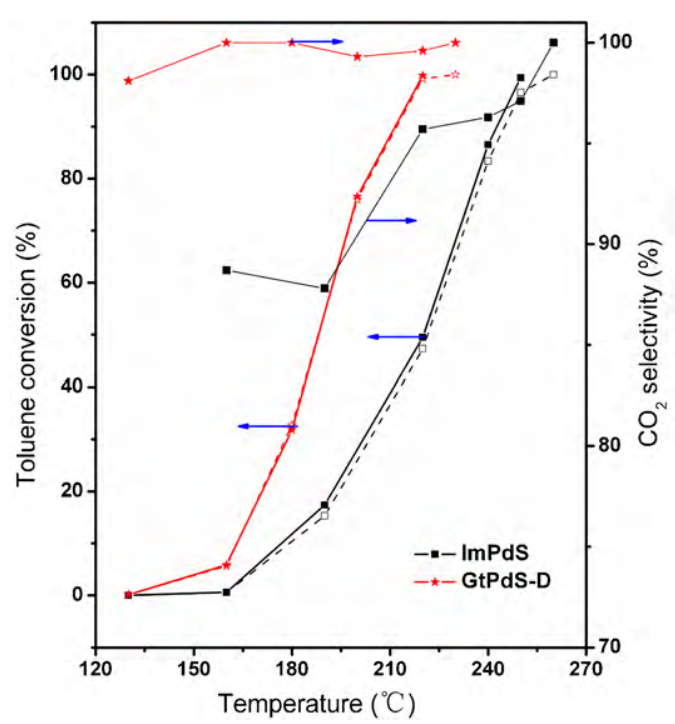

Fig. 8. Conversion and selectivity profiles of toluene oxidation over ImPdS and GtPdS-D. 


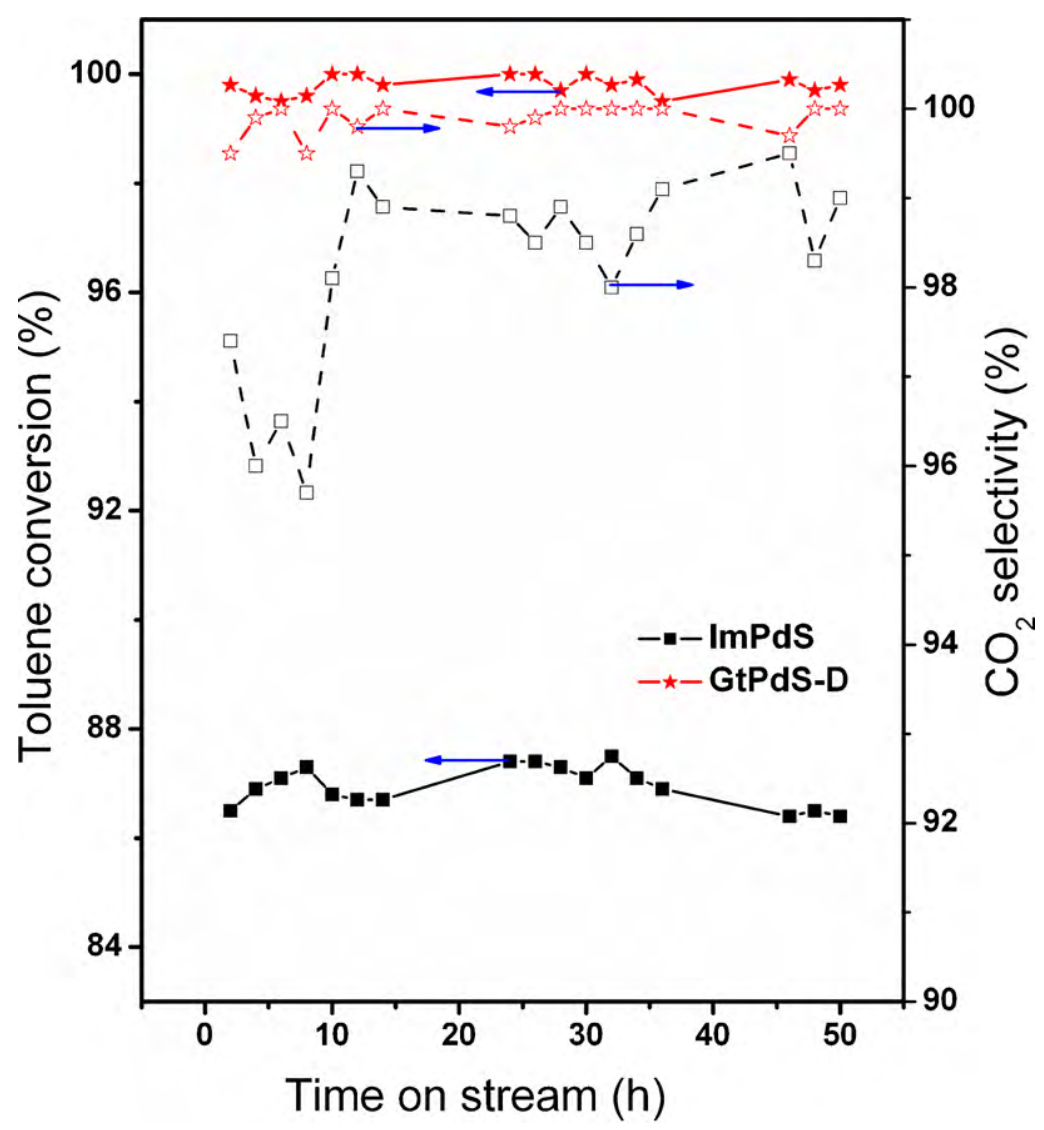

Fig. 9. Stability investigations for toluene combustion with time-on-stream over ImPdS and GtPdS-D.

surface area, i.e., high dispersion of the active phase [36]. Herein, the Pd nanoparticles are well-dispersed in pore channels of SBA15 and the size-restricted mesopores of host silica can effectively prevent the agglomeration of active Pd particles, which resulted in the superior activity of GtPdS-D. However, for ImPdS sample, the impregnated palladium tends to agglomerate on the hydrophobic surface of SBA-15, thus the pore channels could be jammed to some extent, making the active sites in the intermediate position less accessible, and hence reduce the catalytic activity. The stabilities of GtPdS-D and ImPdS were tested for $50 \mathrm{~h}$ under conditions of $600 \mathrm{ppm}$ of toluene in the feed gas, GHSV of $45,000 / \mathrm{h}$, and reaction temperature of 220 and $240^{\circ} \mathrm{C}$ for GtPdS-D and ImPdS, respectively, as shown in Fig. 9. During $50 \mathrm{~h}$ test, the toluene conversion over ImPdS and GtPdS-D is well maintained. Noticeably, the $\mathrm{CO}_{2}$ selectivity of GtPdS-D is also well sustained at $99 \pm 1 \%$.

\section{Conclusions}

The highly active and stable SBA-15 supported catalysts with nanometric Pd located in their pore channels were successfully synthesized. Pd incorporation methods have negligible influence on the original structure of support material, and the grafting is an effective approach to control the location and distribution of Pd atoms in the host silica. The solvents have significant influences on the Pd particle size, and DMF is the preferred solvent in order to get highly dispersed Pd nanoparticles. The catalyst prepared via the grafting procedure catalyzes the toluene far more effectively than that prepared by impregnation method. Both the synthesized catalysts show a good long-term stability, and the toluene conversion and $\mathrm{CO}_{2}$ selectivity can be well-maintained during $50 \mathrm{~h}$ tests. As a consequence, these catalysts are effective and promising materials in control of VOCs emissions.

\section{Acknowledgements}

National Basic Research Program of China (No. 2010CB732300), the National High Technology Research and Development Program of China (No. 2006AA06A310), and National Science Fund for Distinguished Young Scholars (No. 20725723) are gratefully acknowledged.

\section{References}

[1] H. Einaga, A. Ogata, Benzene oxidation with ozone over supported manganese oxide catalysts: effect of catalyst support and reaction conditions, J. Hazard. Mater. 164 (2009) 1236-1241.

[2] C. He, J.J. Li, J. Cheng, L.D. Li, P. Li, Z.P. Hao, Z.P. Xu, Comparative studies on porous material-supported Pd catalysts for catalytic oxidation of benzene, toluene, and ethyl acetate, Ind. Eng. Chem. Res. 48 (2009) 6930-6936.

[3] T. Masui, H. Imadzu, N. Matsuyama, N. Imanaka, Total oxidation of toluene on $\mathrm{Pt} / \mathrm{CeO}_{2}-\mathrm{ZrO}_{2}-\mathrm{Bi}_{2} \mathrm{O}_{3} /$ gamma- $\mathrm{Al}_{2} \mathrm{O}_{3}$ catalysts prepared in the presence of polyvinyl pyrrolidone, J. Hazard. Mater. 176 (2010) 1106-1109.

[4] M. Popova, A. Szegedi, Z. Cherkezova-Zheleva, I. Mitov, N. Kostova, T. Tsoncheva Toluene oxidation on titanium- and iron-modified MCM-41 materials, J. Hazard. Mater. 168 (2009) 226-232.

[5] L.F. Wang, M. Sakurai, H. Kameyama, Catalytic oxidation of dichloromethane and toluene over platinum alumite catalyst, J. Hazard. Mater. 154 (2008) 390-395.

[6] C. He, P. Li, J. Cheng, H. Wang, J. Li, Q. Li, Z. Hao, Synthesis and characterization of Pd/ZSM-5/MCM-48 biporous catalysts with superior activity for benzene oxidation, Appl. Catal. A: Gen. (2010), doi:10.1016/j.apcata.2010.04.033.

[7] S.C. Kim, W.G. Shim, Properties and performance of Pd based catalysts for catalytic oxidation of volatile organic compounds, Appl. Catal. B: Environ. 92 (2009) 429-436.

[8] C. He, J. Li, P. Li, J. Cheng, Z. Hao, Z.-P. Xu, Comprehensive investigation of Pd/ZSM-5/MCM-48 composite catalysts with enhanced activity and stability for benzene oxidation, Appl. Catal. B: Environ. 96 (2010) 466-475.

[9] K. Okumura, T. Kobayashi, H. Tanaka, M. Niwa, Toluene combustion over palladium supported on various metal oxide supports, Appl. Catal. B: Environ. 44 (2003) 325-331

[10] K.J. Kim, H.G. Ahn, Complete oxidation of toluene over bimetallic Pt-Au catalysts supported on $\mathrm{ZnO} / \mathrm{Al}_{2} \mathrm{O}_{3}$, Appl. Catal. B: Environ. 91 (2009) 308-318. 
[11] T. Zhu, J. Li, W.J. Liang, Y.Q. Jin, Synergistic effect of catalyst for oxidation removal of toluene, J. Hazard. Mater. 165 (2009) 1258-1260.

[12] T. Tsoncheva, L. Ivanova, J. Rosenholm, M. Linden, Cobalt oxide species supported on SBA-15, KIT-5 and KIT-6 mesoporous silicas for ethyl acetate total oxidation, Appl. Catal. B: Environ. 89 (2009) 365-374.

[13] Z.J. Wang, Y.B. Xie, C.J. Liu, Synthesis and characterization of noble metal (Pd, $\mathrm{Pt}, \mathrm{Au}, \mathrm{Ag}$ ) nanostructured materials confined in the channels of mesoporous SBA-15, J. Phys. Chem. C 112 (2008) 19818-19824.

[14] O.M. Wilson, M.R. Knecht, J.C. Garcia-Martinez, R.M. Crooks, Effect of Pd nanoparticle size on the catalytic hydrogenation of allyl alcohol, J. Am. Chem. Soc. 128 (2006) 4510-4511.

[15] J.Chou, S. Zhang, S. Sun, E.W. McFarland, Benzene formation at $70^{\circ} \mathrm{C}$ by coupling of propylene on supported Pd nanoclusters, Angew. Chem. Int. Ed. 44 (2005) 4735-4739.

[16] Y. Zhang, F.L.-Y. Lam, X. Hu, Z. Yan, P. Sheng, Fabrication of copper nanowire encapsulated in the pore channels of SBA-15 by metal organic chemical vapor deposition, J. Phys. Chem. C 111 (2007) 12536-12541.

[17] S. Suvanto, J. Hukkamäki, T.T. Pakkanen, T.A. Pakkanen, High-cobalt-loaded MCM-41 via the gas-phase method, Langmuir 16 (2000) 4109-4115.

[18] C. He, P. Li, J. Cheng, Z. Hao, Z.-P. Xu, A comprehensive study of deep catalytic oxidation of benzene, toluene, ethyl acetate, and their mixtures over Pd/ZSM-5 catalyst: mutual effects and kinetics, Water Air Soil Pollut. 209(2010) 365-376.

[19] M.H. Huang, A. Choudrey, P.D. Yang, Ag nanowire formation within mesoporous silica, Chem. Commun. 12 (2000) 1063-1064.

[20] M.E. Grass, Y. Yue, S.E. Habas, R.M. Rioux, C.I. Teall, P. Yang, G.A. Somorjai, Silver ion mediated shape control of platinum nanoparticles: removal of silver by selective etching leads to increased catalytic activity, J. Phys. Chem. C 112 (2008) 4797-4804.

[21] S.S. Lee, H.I. Park, B.K. Park, S.H. Byeon, Influence of solvents on the formation of Pd and PdO nanoparticles in SBA-15, Mater. Sci. Eng. B 135 (2006) 20-24.

[22] K.B. Lee, S.M. Lee, J. Cheon, Size-controlled synthesis of Pd nanowires using a mesoporous silica template via chemical vapor infiltration, Adv. Mater. 13 (2001) 517-520.

[23] C.L. Li, Q.H. Zhang, Y. Wang, H.L. Wan, Preparation, characterization and catalytic activity of palladium nanoparticles encapsulated in SBA-15, Catal. Lett. 120 (2008) 126-136.

[24] D.H. Lin, Y.X. Jiang, Y. Wang, S.G. Sun, Silver nanoparticles confined in SBA15 mesoporous silica and the application as a sensor for detecting hydrogen peroxide, J. Nanomater. 2008 (2008) 1-10.
[25] B. Lee, Z. Ma, Z.T. Zhang, C. Park, S. Dai, Influences of synthesis conditions and mesoporous structures on the gold nanoparticles supported on mesoporous silica hosts, Micropor. Mesopor. Mater. 122 (2009) 160-167.

[26] D.Y. Zhao, J.L. Feng, Q.S. Huo, N. Melosh, G.H. Fredrickson, B.F. Chmelka, G.D. Stucky, Triblock copolymer syntheses of mesoporous silica with periodic 50 to 300 angstrom pores, Science 279 (1998) 548-552.

[27] N. Krishnankutty, J. Li, M.A. Vannice, The effect of Pd precursor and pretreatment on the adsorption and absorption behavior of supported Pd catalysts, Appl. Catal. A: Gen. 173 (1998) 137-144.

[28] J.J. Li, Z. Jiang, Z.P. Hao, X.Y. Xu, Y.H. Zhuang, Pillared laponite clays-supported palladium catalysts for the complete oxidation of benzene, J. Mol. Catal. A: Chem. 225 (2005) 173-179.

[29] C. He, P. Li, J. Cheng, J. Li, Z. Hao, Preparation and investigation of Pd/Ti-SBA15 catalysts for catalytic oxidation of benzene, Environ. Prog. Sustain. Energy (2009), doi:10.1002/ep.10427.

[30] K.S.W. Sing, D.H. Everett, R.A.W. Haul, L. Moscou, R.A. Pierotti, J. Rouquérol, T. Siemieniewska, Reporting physisorption data for gas/solid systems with special reference to the determination of surface area and porosity, Pure Appl. Chem. 57 (1985) 603-619.

[31] P. Han, H.M. Zhang, X.P. Qiu, X.L. Ji, L.X. Gao, Palladium within ionic liquid functionalized mesoporous silica SBA-15 and its catalytic application in roomtemperature Suzuki coupling reaction, J. Mol. Catal. A: Chem. 295(2008) 57-67.

[32] S.W. Song, K. Hidajat, S. Kawi, Functionalized SBA-15 materials as carriers for controlled drug delivery: influence of surface properties on matrix-drug interactions, Langmuir 21 (2005) 9568-9575.

[33] S. Fiorolli, B. Onida, C. Barolo, G. Viscardi, D. Brunel, E. Garrone, Tethering of modified reichardt's dye on SBA-15 mesoporous silica: the effect of the linker flexibility, Langmuir 23 (2007) 2261-2268.

[34] B. Lee, Y. Kim, H. Lee, J. Yi, Synthesis of functionalized porous silicas via templating method as heavy metal ion adsorbents: the introduction of surface hydrophilicity onto the surface of adsorbents, Micropor. Mesopor. Mater. 50 (2001) 77-90.

[35] D.I. Enache, J.K. Edwaeds, P. Landon, B. Solaona-Espriu, A.F. Carley, A.A. Herzing, M. Watanabe, C.J. Kiely, D.W. Knight, G.J. Hutching, Solvent-free oxidation of primary alcohols to aldehydes using $\mathrm{Au}-\mathrm{Pd} / \mathrm{TiO}_{2}$ catalysts, Science 311 (2006) 362-365.

[36] S. Lambert, C. Cellier, E.M. Gaigneaux, J.-P. Pirard, B. Heinrichs, $\mathrm{Ag} / \mathrm{SiO}_{2}, \mathrm{Cu} / \mathrm{SiO}_{2}$ and $\mathrm{Pd} / \mathrm{SiO}_{2}$ cogelled xerogel catalysts for benzene combustion: relationships between operating synthesis variables and catalytic activity, Catal. Commun. 8 (2007) 1244-1248. 